\title{
Localized dental dyschromia-causes and management
}

\author{
(1) Sukanya Dey, (1) Ishani Saluja, (1) Manuel Thomas \\ Manipal College of Dental Sciences, Mangalore, Department of Conservative Dentistry and Endodontics, (Affiliated to Manipal \\ Academy of Higher Education), Karnataka, India
}

Date submitted:

30.11.2020

Date accepted:

05.02.2021

Online publication date: 15.12.2021

\section{Corresponding Author:}

Manuel Thomas, M.D.S, Assoc.

Prof., Manipal College of Dental

Sciences, Mangalore, Department

of Conservative Dentistry and

Endodontics, (Affiliated to Manipal

Academy of Higher Education),

Karnataka, India

manuel.st@manipal.edu

\section{ORCID:}

orcid.org/0000-0002-3042-0669

Keywords: Dental esthetics, tooth discolorations, teeth bleaching

\begin{abstract}
Tooth discoloration is an important aesthetic complaint of patients. Discoloration of teeth can be either localized or generalized. It is essential to recognize the etiology and manage the discoloration accordingly. Localized discolored teeth can be managed by minimally invasive treatment options (such as resin infiltration, microabrasion, macroabrasion or bleaching) and restorative methods (such as composite or ceramic veneers or full coverage crowns). A combination of these treatments may provide a more successful outcome. An overview of the etiology of localized anterior discolored tooth, and the prevention and management of such clinical cases are discussed in this article.
\end{abstract}

\section{Introduction}

Localized discoloration of anterior teeth may present as an important aesthetic concern for many patients. The management of such teeth poses a challenge to the clinician, and obtaining an aesthetic outcome in keeping with the patient's treatment needs is often difficult (1). There are various approaches for the treatment of such discolored teeth and the selection of a particular mode of treatment may depend on factors such as the cause of discoloration, history of previous treatment performed on the teeth, amount of remaining coronal tooth structure, the patient's aesthetic needs, and financial concerns (2). Management of such teeth can range from minimally invasive treatment options such as resin infiltration, microabrasion, macroabrasion and bleaching to restorative options such as veneers or full coverage crowns (3). It is essential to carefully assess and diagnose the affected teeth in order to select a management strategy that would be best suited to the patient's needs. Certain cases would require a combination of treatment modalities in order to achieve the desired treatment outcome. This article aims to provide an overview of the etiology, diagnosis and the various treatment options available for the management of localized anterior discolored teeth.

\section{Etiopathogenesis}

An understanding of the reason for tooth discoloration will help in (i) making the correct diagnosis (ii) explaining the condition to the patient (iii) and selecting the appropriate treatment option. The causes for localized tooth discoloration have been summarized in Table 1 (4-7). 


\section{Diagnosis}

\section{History}

The clinician must record a proper case history, focusing on the discolored tooth in question, in order to correctly diagnose the etiology of the discoloration. This should be done in a systematic and methodical manner. The chief complaint would provide an indication for the patient's aesthetic needs as well. The patient should be asked detailed questions regarding the duration of discoloration, any precipitating factors, history of habits such as smoking, history of pain, trauma and history of previous dental treatment (2).

If the patient provides a history of traumatic dental injury, the clinician must ask about the time of occurrence of the traumatic injury, type of trauma, and the treatment done at the time. In certain cases, a reversible pink discoloration may be noted in traumatic teeth which appear 2-3 days after the injury and do not require any treatment other than monitoring at recall appointments. If the pulp of a traumatized tooth recovers or undergoes revascularization, the discoloration can be resolved in 2-3 months. In some cases, the discoloration may only appear 2-3 months after the trauma (8).

\section{Clinical Examination}

The next step involves conducting a proper clinical examination in order to reach a correct diagnosis (2). Non-vital teeth often present with a wide variety of discolorations which can be attributed to the etiology of discoloration, as have been outlined in Table 1. Teeth with partial or complete pulp canal obliteration are usually asymptomatic. They may exhibit mild symptoms like apical periodontitis only if there is the presence of infected tissue in the pulp space (9).

\section{Aesthetic Evaluation}

The clinical examination must also include a comprehensive aesthetic evaluation. The shade of the discolored tooth and the adjacent teeth must be evaluated and recorded. The clinician must evaluate the dimensions of the affected and adjacent teeth, smile symmetry, amount of gingival display on smiling, gingival architecture and lip lines. Any additional white spot or brown spot lesions, enamel translucencies and pre-existing restorations should also be checked. The quality and quantity of the remaining coronal structure should be evaluated and the patient must be informed about his treatment options (2).

If bleaching is planned for patients with pre-existing white spot lesions, they should be informed that these may become more distinguishable in the first few days after bleaching. This phenomenon is known as the 'splotchy stage' of the treatment and it happens due to the penetration of the bleaching agent into the white spot lesion first, since it is the weakest part of the tooth (10). After bleaching is completed, the condition may resolve by itself or further treatment in the form of micro-abrasion or

\begin{tabular}{|c|c|c|}
\hline Cause & Condition & Color \\
\hline Traumatic causes & $\begin{array}{l}\text { - Enamel hypoplasia } \\
\text { - Dentin hyper-calcification } \\
\text { - Internal resorption/external cervical resorption } \\
\text { - Calcific metamorphosis } \\
\text { - Intra-pulpal hemorrhage } \\
\text { - Pulp necrosis } \\
\text { With hemorrhage } \\
\text { Without hemorrhage }\end{array}$ & $\begin{array}{l}\text { White or yellow-brown } \\
\text { Yellow or brown } \\
\text { Pink } \\
\text { Yellow } \\
\text { Gray or brown } \\
\text { Gray or black } \\
\text { Yellow, gray-brown }\end{array}$ \\
\hline latrogenic causes & $\begin{array}{l}\text { - Trauma during pulp extirpation } \\
\text { - Tissue remnants in pulp chamber } \\
\text { - Inappropriate design of access cavity (traps pulp } \\
\text { chromophore materials inside the pulp chamber) } \\
\text { - Products of tissue decomposition } \\
\text { - Dental restorative materials (e.g. grey MTA, Amalgam, zinc } \\
\text { oxide eugenol etc.) } \\
\text { - Endodontic materials (root canal irrigant, intracanal } \\
\text { medicaments, sealers and gutta percha) }\end{array}$ & $\begin{array}{l}\text { Gray or black } \\
\text { Brown, gray or black } \\
\text { Yellow, gray } \\
\text { Yellow, brown or gray } \\
\text { Brown, gray or black } \\
\text { Gray or black }\end{array}$ \\
\hline Internalized & - Caries & White spot lesion to black arrested lesion \\
\hline Extrinsic causes & - Discolored restoration & Yellow or brown \\
\hline Extrinsic and intrinsic causes & $\begin{array}{l}\text { - Localized fluorosis } \\
\text { - Erosion }\end{array}$ & $\begin{array}{l}\text { Chalky white or dark brown/black } \\
\text { Brown }\end{array}$ \\
\hline Idiopathic causes & - Molar-incisor hypo-mineralization & White, yellow or brown \\
\hline Congenital causes & - Regional odontodysplasia & Yellow or yellowish brown \\
\hline
\end{tabular}


resin infiltration may be indicated. Pre-existing restorations in the anterior region may need to be replaced since their shade may not match with that of the adjacent bleached teeth (2).

\section{Radiographic Assessment and Pulp Testing}

Thermal and electric pulp testing should be carried out for all discolored teeth, in order to assess their vitality. Traumatized teeth may have necrosed pulps and would thus yield a negative response to pulp vitality tests. Thermal pulp tests of teeth with pulp canal obliteration do not usually yield a positive response. Electric pulp tests for such teeth may give a normal or delayed response (9).

For teeth with calcific metamorphosis, complete or partial obliteration of the pulp chamber and pulp canal space may be seen, which occurs from the coronal to the apical direction. The periodontal ligament (PDL) space usually appears normal, intact lamina dura. If calcific metamorphosis is associated with apical periodontitis, widening of the PDL space or peri-radicular radiolucency may be noticed in chronic cases (11).

In cases of pulp necrosis associated with trauma/caries, periapical radiolucency with widening of PDL space may be observed in some cases. Periapical radiolucency with bone loss may be noted in case of periapical cysts or radicular cysts (12).

In internal resorption, round or oval radiolucent areas may be seen within the pulp chamber, with loss of dentin, and distortion of pulp space anatomy (13). Teeth with external cervical root resorption may show either asymmetric radiolucency in the cervical/proximal aspect of the tooth with irregular margins or uniform circular radiolucency centered over the root. These lesions may initially appear radiolucent, whereas advanced lesions may present with a mottled appearance due to the fibroosseous nature of the lesion. In most cases, the root canal would remain patent and would be radiographically discernible (14).

In regional odontogenic dysplasia, the teeth exhibit a ghost like appearance radiographically, with thin enamel (15).

\section{Prevention}

Prevention of tooth discoloration, if possible, should always be the first line of management of discolored teeth. There are a few preventive measures that should be followed by the clinician in order to avoid discoloration at a later stage. To prevent intrinsic discoloration due to caries, in initial stages of the carious lesion, treatment should include topical fluoride therapy and application of pit and fissure sealants. Later, in cavitation stages, it is always better to avoid amalgam restorations especially in the aesthetic areas, and the use of tooth colored restorations, such as composite resins or ceramic restorations, is preferred.

The use of grey mineral trioxide aggregate (MTA) may cause a greyish discoloration of the tooth, hence use of white MTA is preferred. During the endodontic access cavity preparation, it is always advisable to completely remove pulp tissue and pulpal remnants and pulp horns, by adequate deroofing as well as by agitating sodium hypochlorite. The use of triple antibiotic paste as an intracanal medicament may cause discoloration since minocycline is one of the components, hence double antibiotic paste may be used (16). Irrigation with chlorhexidine immediately after using sodium hypochlorite may form brownishred precipitates. Hence, distilled water or saline or even sodium metabisulfite have been suggested as an in between flush to prevent the formation of this precipitate (17). After root canal filling, it is mandatory to clear the obturating materials [core material and root canal sealer] from the pulp chamber to avoid coronal color change.

\section{Management}

Various factors need to be considered while developing a treatment plan for teeth with localized discoloration. A flow chart has been prepared for ease in decision making (Figure 1).

\section{Scaling and Polishing}

The first step in the treatment of tooth discoloration should be scaling and polishing, which will help in the removal of extrinsic stains, allowing the dentist to evaluate the actual underlying tooth shade (16).

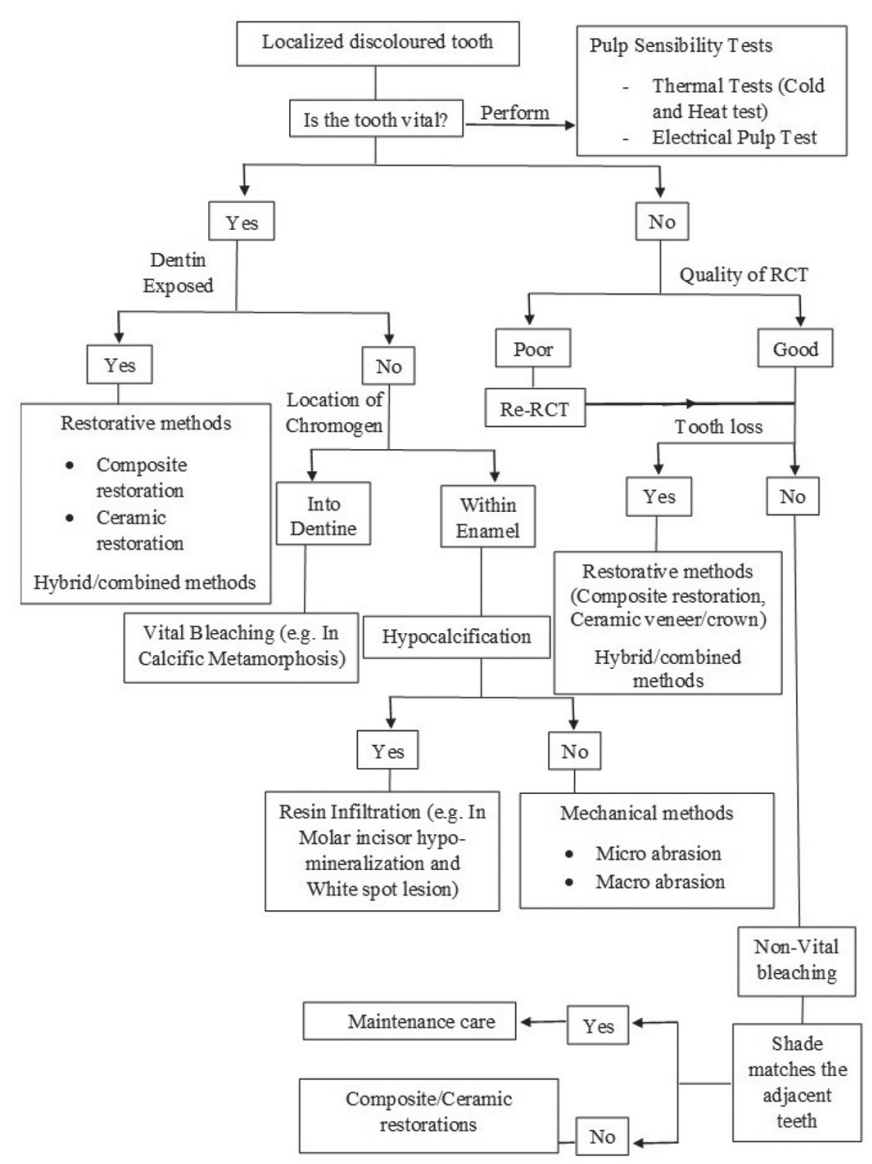

Figure 1. Treatment decision algorithm for localized dental dyschromia RCT: Randomized clinical trial 


\section{Air Polishing}

Air polishing is a procedure in which a substance like calcium carbonate, sodium bicarbonate or aluminum tri-hydrate is ejected through a mixing nozzle with air and water. This is used in the form of a controlled jet against tooth enamel. This is a rapid method for the removal of extrinsic stains (18). However, air polishing with sodium bicarbonate abrades dentine and cementum and hence it is better to avoid its usage since it can lead to increased post-operative dental sensitivity. Alternatively, bioactive glass air-polishing was shown to be more effective at desensitizing and removing stains (19).

\section{Resin Infiltration}

Resin infiltration can be used for the management of noncavitated carious or hypomineralised lesions on the smooth or proximal surfaces of primary and permanent teeth. This preserves tooth structure, is relatively non-invasive, and can be accomplished in a single appointment (20).

The objective of resin infiltration is the occlusion of the microporosities within the body of the lesion by infiltrating lightcuring resins of low viscosity (21). Scattering of light occurs due to the difference in refractive indices between the air or water inside the porosities and the enamel crystals, resulting in an opaque whitish appearance. When the microporosities are filled with resin, there is a little difference in refractive indices between the porosities and enamel and the lesions become practically indistinguishable from the surrounding sound enamel (22). Hence, resin infiltration is useful in the treatment of initial enamel caries and improvement in the appearance of white spot lesions, and mild cases of fluorosis (23).

Caries progression is inhibited by sequentially applying $15 \%$ hydrochloric acid gel for two minutes. This is followed by applying a low viscosity tri-ethylene glycol dimethacrylate resin, with a sufficiently high penetration coefficient (22).

\section{Microabrasion}

This involves simultaneous erosion and abrasion of a microscopic layer of enamel leaving behind an intact surface. This amorphous, prismless layer has a smooth and lustrous appearance. Microabrasion may be carried out along with vital bleaching or direct composite resin veneers for improving the appearance of severely discolored teeth with developmental defects or superficial stains (16). Kits for microabrasion are commercially available. An alternative is to use $37 \%$ phosphoric acid gel and pumice. Microabrasion removes about 50-200 microns of the surface layer of enamel so it should not be done repeatedly (22). If carried out properly, microabrasion should lead to only negligible loss of enamel, no damage to pulp or periodontal tissues, and produce satisfactory and permanent results in a short time period without causing any discomfort to the patient (24).

\section{Macroabrasion}

Magne was the first to describe macroabrasion or megabrasion (25). Macroabrasion is useful for the treatment of enamel opacities and yellowish-brown discolorations of enamel (16). Macroabrasion mechanically eradicates the lesion so that it can be restored with a direct composite resin. The optical appearance of the tooth is attributed to the intact underlying dentine, and the surface morphology of the tooth can be recreated by applying a neutral, translucent and slightly fluorescent resin composite. A coarse diamond instrument is used at low speeds $(400-2000 \mathrm{rpm})$ to eliminate the discolored enamel in a safe and controlled manner. Sharp angles are removed with the help of coarse flexible discs. The defects can then be restored with composite resin to achieve an aesthetic appearance (16). Macroabrasion can be a possible treatment option for severe dental fluorosis without unnecessary removal of dental hard tissues (26).

\section{Bleaching of Teeth}

One of the most conservative, economical and safe treatment options for the management of a single discolored tooth is bleaching. The method of bleaching should depend on whether the tooth is vital or not, and whether the procedure would be carried out at home, or in the dentist's clinic. For vital teeth and teeth with radiographic evidence of pulp canal obliteration, an external approach may be adopted. For previously endodontically treated teeth, walking bleach technique or the inside-outside bleaching technique can be followed (1). Bleaching can be broadly categorized into vital and non-vital bleaching.

\section{Vital Bleaching}

Vital bleaching is a non-invasive procedure that can be carried out either through the use of various home-based gels or through in-office bleaching. $10 \%$ carbamide peroxide gel loaded into a tray can be used for vital tooth bleaching since it has reduced the risk of causing dentinal hypersensitivity and irritation to the adjacent soft tissues in comparison with more concentrated gels (27). It can be used for the treatment of single discolored teeth due to calcific metamorphosis, white and brown discolorations from mild fluorosis (16) or localized yellow and brown hypoplastic lesions (28). Vital bleaching is performed prior to further aesthetic treatment, such as macroabrasion, microabrasion and/or direct composite resin veneers.

\section{Non-vital Bleaching}

This is carried out to treat minimally restored teeth that have undergone discoloration as a result of necrotic pulpal remnants left behind in the pulp chamber after endodontic treatment or pulpal hemorrhage into the dentine due to dental trauma (29). In intracoronal bleaching, oxidizing agents are used in the pulp chamber of an endodontically treated tooth for the removal of discoloration (Figure 2) (2). The following methods can be employed for non-vital bleaching of teeth: 


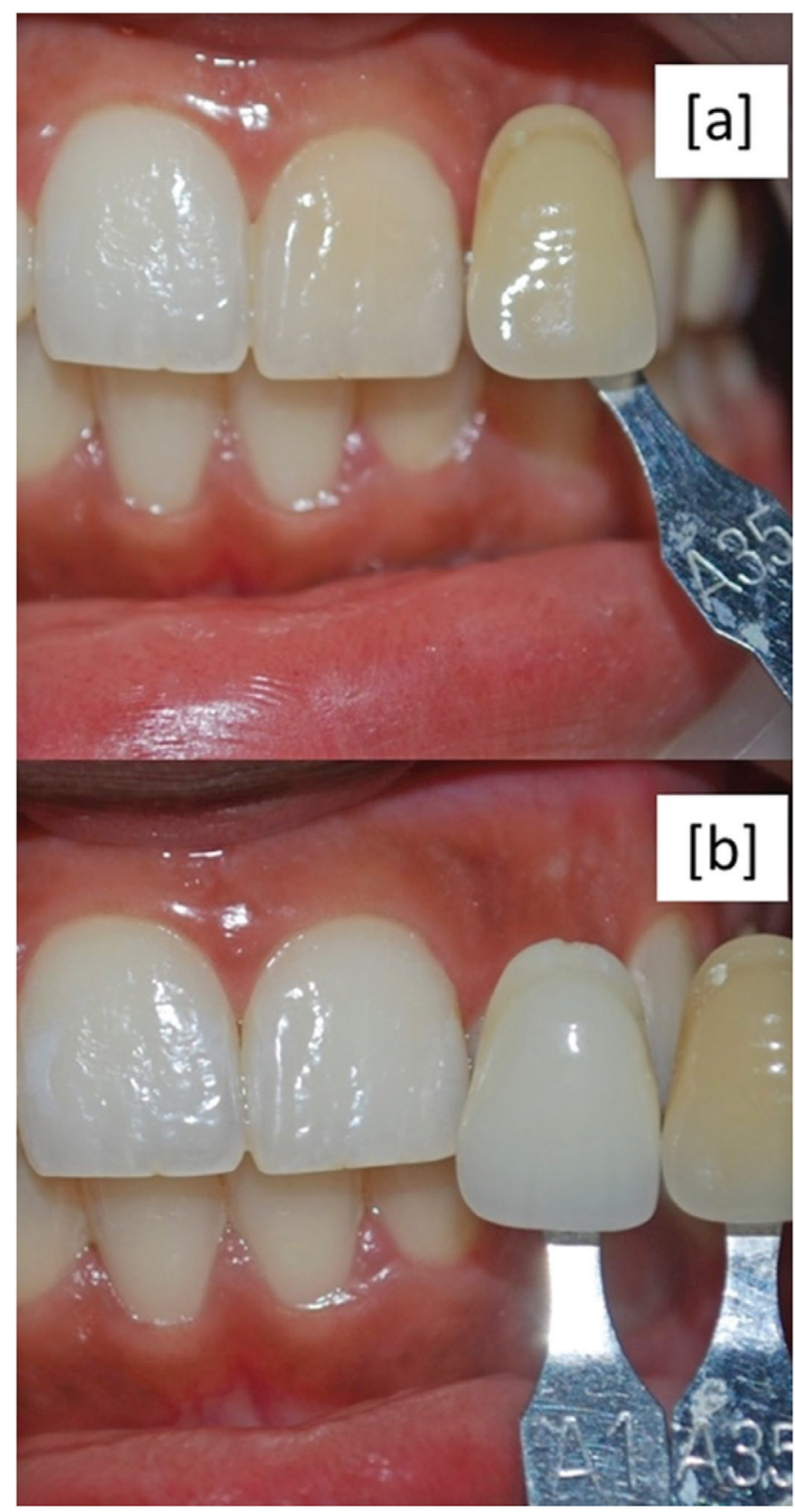

Figure 2. Non-vital walking bleach technique (a) Pre-operative image showing yellowish discoloration on tooth number \#21 (b) Post-operative image after two rounds of non-vital bleaching

i. In-office bleaching: Traditionally, in-office bleaching involves internal or external application of high concentrations of hydrogen peroxide or hydrogen peroxide mixed with sodium perborate. An alternative would be supplementation of the bleaching agent with heat, known as thermocatalytic bleaching. A disadvantage of this technique is that shade matching becomes difficult due to dehydration and demineralization because of the high concentration and low $\mathrm{pH}$ of hydrogen peroxide used. This method also has increased tendency of side effects like external cervical root resorption due to the use of high concentrations of hydrogen peroxide and heat (2). ii. Walking bleach technique: In the walking bleach technique, after cervical barrier placement with glass-ionomer cement, the bleaching agent is placed above the barrier in the pulp chamber. The endodontic access cavity is then restored with an interim restorative material. The patient is recalled after two weeks for re-evaluation of shade and the method is repeated as necessary until the desired shade is obtained (2).

iii. Inside/outside open technique: In this method, after cervical barrier placement, the access cavity is left open without placing a seal and the patient uses a syringe to apply the bleaching agent directly into the bleaching tray and the access cavity. The bleaching tray is then positioned carefully in the mouth such that the access cavity is covered. The patient is instructed to replace the bleaching agent at 4-6 hour intervals. The patient is recalled after 2-3 days to re-evaluate the amount of bleaching the tooth has undergone (2).

iv. Inside/outside closed technique: This technique has been modified from the inside/outside technique described above. After the placement of a cervical barrier, the bleaching agent is placed in the pulp chamber, and an interim restoration is placed to obtain a coronal seal. Then, a 'single tooth' bleaching tray is used externally to apply the bleaching agent. The patient is told to wear the bleaching tray overnight until the desired shade is obtained or until the patient is recalled for follow-up. The bleaching agent can be reapplied intracoronally, if required, at the review appointment $(2,30)$. This technique is associated with reduced chances of microleakage, damage to the coronal seal, and it prevents food lodgment. Also, the clinician is able to control the progression of the shade (2).

\section{Composite Resin Veneer}

Thin layer of composite resin is applied directly over the entire labial surface of the discolored tooth to correct the shade and modify the contours. This is often preceded by bleaching, resin infiltration, microabrasion or macroabrasion to obtain a substrate with a more uniform shade. Direct composite veneers are indicated for young patients with minimally restored teeth since there is no unnecessary removal of tooth structure. They can be carried out in a single appointment and offer aesthetic results (31).

Indirect composite veneers are an alternative option for masking underlying tooth discoloration or simulating the discoloration of adjacent teeth. The amount of background effect and overall shade can be altered by the light absorption and internal reflection properties of the resin composite. The more the translucency of the composite resin, the more the effect of the stump shade on the final restoration (32). The shade, thickness and optical properties of the resin luting cement might also influence the final appearance of the veneer (33). CAD-CAM fabricated indirect composite veneers allow better 
replication of contacts and surface morphology, especially if there is partial loss of coronal structure, hypoplasia or the tooth is a microdont (31).

\section{Ceramic Veneers}

Porcelain laminate veneers help to mask discolored teeth and replicate the natural shade of the tooth. They can be used for mildly discolored single teeth, when bleaching has not provided a suitable aesthetic result (Figure 3) (31). Ceramic veneers are more resistant to wear than composite veneers (34). Porcelain laminate veneers are also indicated when the adjacent teeth have ceramic prostheses or restorations (31). For severely discolored single tooth, a minimum thickness of $2 \mathrm{~mm}$ of glassceramic is needed in order to achieve the desired final shade (35). The underlying tooth structure affects the final appearance of the ceramic restoration. The color of the substrate (i.e. the stump shade) can be masked by increasing the thickness of the ceramic material, using opaque luting cement, using high opacity zirconia material, or using ceramic systems containing a ceramic substructure with shade-masking properties (36).

\section{Full Coverage Crowns}

These are usually indicated for heavily restored, discolored teeth or endodontically treated teeth restored with post. Crowns should only be considered when more minimally invasive treatment options have not been effective. Full coverage crowns can be either metal-ceramic or all ceramic. Discolored teeth can be restored with either translucent crowns or crowns with opaque cores. Lithium disilicate crowns are a good option for teeth with mild discolorations and can be adhesively bonded to unretentive tooth preparations, such as teeth with oblique fractures or severely worn teeth. For severely discolored teeth, opaque crowns (metal-ceramic or all-ceramic [zirconia]) are a better option since the clinician is able to better predict the final shade of the crown (Figure 3) (37).

\section{Conclusion}

Simple measures can be taken to avoid iatrogenic causes for tooth discoloration post-endodontically. For an already discolored teeth, understanding of the cause for localized tooth discoloration is important in selecting the appropriate treatment option. After recording a thorough history, conducting an oral examination and arriving at a diagnosis, clinicians are recommended to begin with minimally invasive treatment options, followed by the more invasive ones. Certain patients may even require a combination of different types of treatment in order to achieve desirable results. Based on the patient's clinical condition, the severity of discoloration and the aesthetic requirements, the clinician can opt for the appropriate treatment plan. Hence, it is essential for the dentist to possess a thorough knowledge of the treatment modalities available, in order to reach a favorable treatment outcome.

\section{Acknowledgements}

Authors would also like to thank Dr. K. Shanthana Reddy (Post Graduate Student, Department of Conservative Dentistry and Endodontics) for her assistance in reviewing and editing the manuscript.

\section{Ethics}

Peer-review: Externally peer-reviewed.

\section{Authorship Contributions}

Surgical and Medical Practices: S.D., M.T., Concept: S.D., M.T., Design: I.S., Literature Search: S.D., I.S., M.T., Writing: S.D., I.S., M.T.

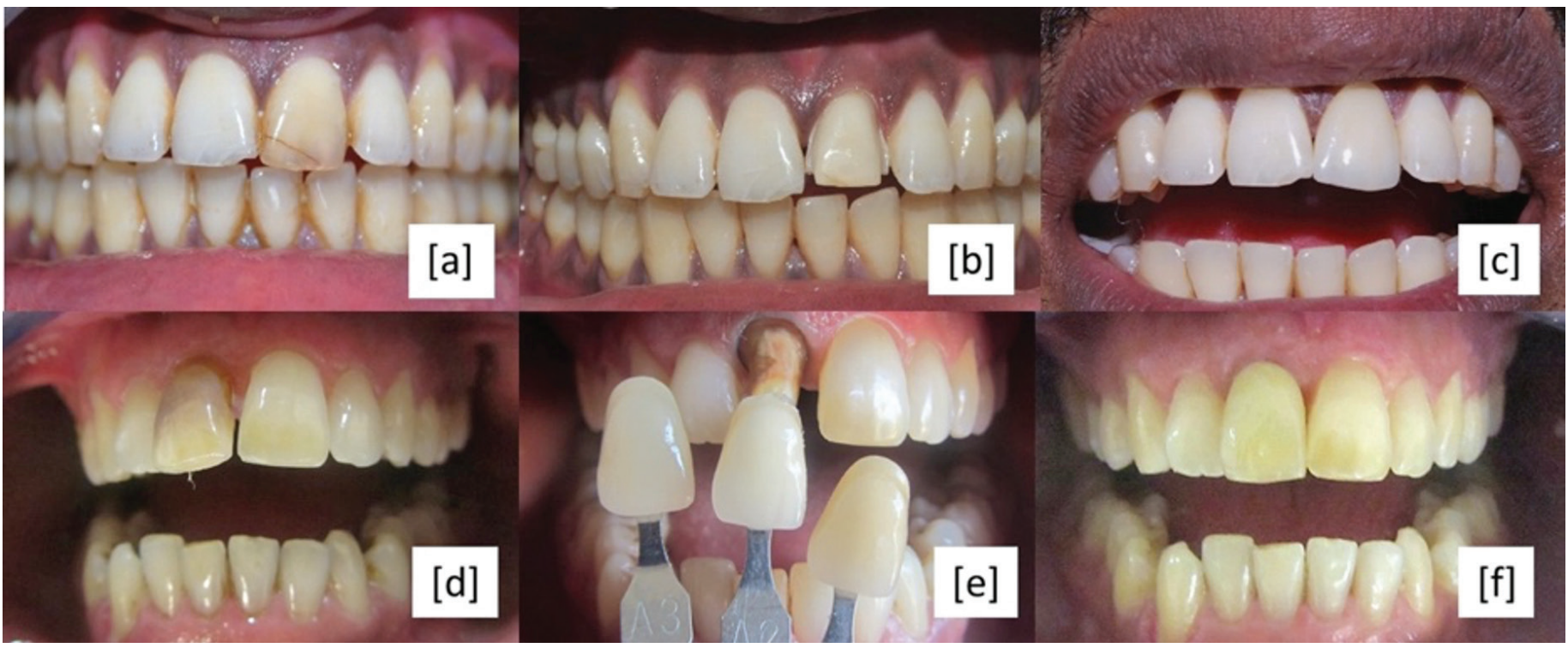

Figure 3. Restorative methods in managing localized discoloration (a to c): Lithium disilicate veneer to mask the discoloration on tooth \#21; (d to e) Zirconia crown to mask the discoloration and to realign tooth \#11 
Conflict of Interest: No conflict of interest was declared by the authors.

Financial Disclosure: The authors declared that this study received no financial support.

\section{References}

1. Kwon SR. Whitening the single discolored tooth. Dent Clin North Am. 2011;55:229-239.

2. Greenwall-Cohen J, Greenwall LH. The single discoloured tooth: vital and non-vital bleaching techniques. $\mathrm{Br}$ Dent $\mathrm{J}$. 2019;226:839-849.

3. Watts A, Addy M. Tooth discolouration and staining: a review of the literature. Br Dent J. 2001;190:309-316.

4. Plotino G, Buono L, Grande NM, Pameijer CH, Somma F. Nonvital tooth bleaching: a review of the literature and clinical procedures. J Endod. 2008;34:394-407.

5. Sulieman M. An overview of tooth discoloration: extrinsic, intrinsic and internalized stains. Dent Update. 2005;32:463464, 466-468, 471.

6. Ahmed HM, Abbott PV. Discolouration potential of endodontic procedures and materials: a review. Int Endod J. 2012;45:883-897.

7. Magalhães AC, Pessan JP, Cunha RF, Delbem AC. Regional odontodysplasia: case report. J Appl Oral Sci. 2007; 15:465-469.

8. Andreasen JO, Andreasen FM, Andersson L. Textbook and Colour Atlas of Traumatic Injuries to the Teeth. 4th ed. Oxford: Wiley-Blackwell; 2007.

9. Haywood VB, Sword RJ. Tooth bleaching questions answered. Br Dent J. 2017;223:369-380.

10. McCabe PS, Dummer PM. Pulp canal obliteration: an endodontic diagnosis and treatment challenge. Int Endod J. 2012;45:177-197.

11. Patel $S$, Kanagasingam S, Pitt Ford T. External cervical resorption: a review. J Endod. 2009;35:616-625.

12. Malhotra N, Mala K. Calcific metamorphosis. Literature review and clinical strategies. Dent Update. 2013;40:4850, 53-54, 57-58.

13. Oginni AO, Adekoya-Sofowora CA. Pulpal sequelae after trauma to anterior teeth among adult Nigerian dental patients. BMC Oral Health. 2007;7:11.

14. Silveira FF, Nunes E, Soares JA, Ferreira CL, Rotstein I. Double 'pink tooth' associated with extensive internal root resorption after orthodontic treatment: a case report. Dent Traumatol. 2009;25:e43-44.

15. Rajendran A, Sivapathasundharam B. Shafer's Textbook of Oral Pathology. 7th ed. Delhi: Reed Elsevier India Private Limited; 2012.

16. Barber A, King P. Management of the single discoloured tooth. Part 1: Aetiology, prevention and minimally invasive restorative options. Dent Update. 2014;41:98-100.
17. Chhabra N, Gangaramani S, Singbal KP, Desai K, Gupta $\mathrm{K}$. Efficacy of various solutions in preventing orangebrown precipitate formed during alternate use of sodium hypochlorite and chlorhexidine: An in vitro study. J Conserv Dent. 2018;21:428-432.

18. Gutmann ME. Air polishing: a comprehensive review of the literature. J Dent Hyg. 1998;72:47-56.

19. Banerjee A, Hajatdoost-Sani M, Farrell S, Thompson I. A clinical evaluation and comparison of bioactive glass and sodium bicarbonate air-polishing powders. J Dent. 2010;38:475-479.

20. Schnabl D, Dudasne-Orosz V, Glueckert R, Handschuh S, Kapferer-Seebacher I, Dumfahrt H. Testing the Clinical Applicability of Resin Infiltration of Developmental Enamel Hypomineralization Lesions Using an In Vitro Model. Int J Clin Pediatr Dent. 2019;12:126-132.

21. Paris $\mathrm{S}$, Meyer-Lueckel $\mathrm{H}$, Kielbassa AM. Resin infiltration of natural caries lesions. J Dent Res. 2007;86:662-666.

22. Nixon PJ, Robinson S, Gahan Matthew, Chan MF. Conservative aesthetic techniques for discoloured teeth: 2 . Microabrasion and composite. Dent Update. 2007;34:160162.

23. Garg SA, Chavda SM. Color Masking White Fluorotic Spots by Resin Infiltration and Its Quantitation by Computerized Photographic Analysis: A 12-month Follow-up Study. Oper Dent. 2020;45:1-9.

24. Balan B, Madanda Uthaiah C, Narayanan S, Mookalamada Monnappa P. Microabrasion: an effective method for improvement of esthetics in dentistry. Case Rep Dent. 2013;2013:951589.

25. Magne P. Megabrasion: a conservative strategy for the anterior dentition. Pract Periodontics Aesthet Dent. 1997;9:389-395.

26. Wang Y, Sa Y, Liang S, Jiang T. Minimally invasive treatment for esthetic management of severe dental fluorosis: a case report. Oper Dent. 2013;38:358-362.

27. Hasson H, Ismail Al, Neiva G. Home-based chemicallyinduced whitening of teeth in adults. Cochrane Database Syst Rev. 2006:CD006202.

28. Dahl JE, Pallesen U. Tooth bleaching--a critical review of the biological aspects. Crit Rev Oral Biol Med. 2003;14:292304.

29. Dietschi D. Nonvital bleaching: general considerations and report of two failure cases. Eur J Esthet Dent. 2006;1:5261.

30. Coelho AS, Garrido L, Mota M, et al. Non-Vital Tooth Bleaching Techniques: A Systematic Review. Coatings. 2020;10:61.

31. Barber AJ, King PA. Management of the single discoloured tooth. Part 2: Restorative options. Dent Update. 2014;41:194-196, 198-200, 202-204.

32. Jarad FD, Griffiths CE, Jaffri M, Adeyemi AA, Youngson $\mathrm{CC}$. The effect of bleaching, varying the shade or thickness 
of composite veneers on final colour: an in vitro study. $\mathrm{J}$ Dent. 2008;36:554-559.

33. de Azevedo Cubas GB, Camacho GB, Demarco FF, Pereira-Cenci T. The Effect of Luting Agents and Ceramic Thickness on the Color Variation of Different Ceramics against a Chromatic Background. Eur J Dent. 2011;5:245252.

34. Vanoorbeek S, Vandamme K, Lijnen I, Naert I. Computeraided designed/computer-assisted manufactured composite resin versus ceramic single-tooth restorations: a 3-year clinical study. Int J Prosthodont. 2010;23:223-230.
35. Vichi A, Ferrari M, Davidson CL. Influence of ceramic and cement thickness on the masking of various types of opaque posts. J Prosthet Dent. 2000;83:412-417.

36. Alshouibi E, Alaqil F. Masking a Metal Cast Post and Core Using High Opacity e.max Ceramic Coping: A Case Report. J Int Soc Prev Community Dent. 2019;9:646-651.

37. Spear F, Holloway J. Which all-ceramic system is optimal for anterior esthetics? J Am Dent Assoc. 2008;139(Suppl):19S$24 S$. 